\title{
Granule for Syrup Dosage Form
}

National Cancer Institute

\section{Source}

National Cancer Institute. Granule for Syrup Dosage Form. NCI Thesaurus. Code C149553.

Solid preparation consisting of aggregated particles that may include excipients to facilitate wetting and dissolution and to obtain the characteristics of a syrup, intended to be dissolved in water to obtain a syrup. 